\title{
Gastronomi turizminin gelişmesinde tarihi Afyonkarahisar konaklarının önemi*
}

\section{The significance of historical Afyonkarahisar mansions in the development of gastronomy tourism}

Gönderim Tarihi / Received: 19.11 .2021

Kabul Tarihi / Accepted: 23.12.2021

doi https://doi.org/10.31795/baunsobed.1026048

\section{Ömer SARAÇ*1 \\ Tolga KAYA ${ }^{2}$ \\ Hüseyin PAMUKÇU ${ }^{3}$ \\ Mustafa SANDIKÇI $I^{4}$}

ÖZ: Şehir kültürünün bir parçası olan tarihi konaklar, restore edilerek ve yeniden işlevlendirilerek son zamanlarda kafe, restoran ve otel olarak hizmet vermektedir. Türkiye'nin birçok ilinde yeniden işlevlendirilmiş tarihi konaklar bulunmaktadır. Afyonkarahisar da bu illerden biridir. Afyonkarahisar'da bulunan tarihi konakların geçmişi 1900'lü yıllara kadar dayanmaktadır. Bu araştırmanın amacı gastronomi turizminin gelişmesinde Afyonkarahisar'da bulunan tarihi konakların ne düzeyde önemli olduğunun ortaya konulmasıdır. Araştırmada nitel veri toplama yöntemine başvurulmuştur. Afyonkarahisar kent merkezinde restoran olarak işlevlendirilmiş tarihi konaklar, araştırmanın uygulama alanı olarak belirlenmiştir. Bu doğrultuda beş işletme yöneticisi ve işvereni ile görüşülmüş veriler yarı yapılandırılmış görüşme formu ile elde edilmiştir. Elde edilen veriler içerik analizi tekniği ile çözümlenmiş̧ir. Araştırma sonuçlarına göre tarihi konaklar 23 farklı yöresel yemeğin sunumunu yapmakta ve Afyonkarahisar mutfak kültürünü iyi bir şekilde yansitmaktadır. Ayrıca tarihi Afyonkarahisar konaklarının gastronomi turizmi kapsamında gerekli pazarlama ve reklam çalışmaları ile başarılı bir destinasyon merkezi olacağı sonuca ulaşılmıştır.

Anahtar Kelimeler: Kültürel sürdürülebilirlik, Tarihi konaklar, Gastronomi turizmi, Afyonkarahisar

ABSTRACT: Historical mansions, which are a part of the culture of the city, have been restored and re-functioned recently and have been serving as cafes, restaurants, and hotels. There are many historical mansions that have been re-functionalized in many provinces of Turkey. One of these provinces is Afyonkarahisar. The history of historical mansions in Afyonkarahisar dates back to the 1900s. This research aims to reveal how important the historical mansions in Afyonkarahisar are in the development of gastronomic tourism. A qualitative data collection method was applied in the study. The historical mansions which are functioned as restaurants in Afyonkarahisar city centre were determined as the application area of the research. In this direction, five business managers and employers were interviewed and the data were obtained with a semi-structured interview form. The obtained data were analyzed by the content analysis technique. According to the results of this research, the historical mansions presented 23 different local dishes and reflected the culinary culture of Afyonkarahisar well. In addition, it has been concluded that Afyonkarahisar historical mansions will be a successful destination centre with the necessary marketing and advertising activities within the scope of gastronomy tourism.

Keywords: Cultural sustainability, Historical mansions, Gastronomy tourism, Afyonkarahisar

\footnotetext{
* Bu makale 21. Ulusal 5. Uluslararası Turizm Kongresinde sunulan “Afyonkarahisar Tarihi Konak İşletmelerinin Gastronomi Turizmi Kapsamında Değerlendirilmesi” başlıklı bildiriden türetilmiştir.

** Sorumlu Yazar / Corresponding Author

${ }^{1}$ Dr. Öğr. Üyesi, Sakarya Uygulamalı Bilimler Üniversitesi/Turizm Fakültesi/Turizm İşletmeciliği Bölümü/Turizm İşletmeciliği Anabilim Dal1, omersarac@ @ubu.edu.tr, https://orcid.org/0000-0002-4338-7394

${ }^{2}$ Yüksek Lisans Öğrencisi, Afyon Kocatepe Üniversitesi/ Sosyal Bilimler Enstitüsü/ Gastronomi ve Mutfak Sanatları Anabilim Dalı, seftolgakaya@gmail.com, https://orcid.org/0000-0002-8357-125X

${ }^{3}$ Doç. Dr., Afyon Kocatepe Üniversitesi/Turizm Fakültesi/Turizm İşletmeciliği Bölümü/Turizm İşletmeciliği Anabilim Dalı, hpamukcu@aku.edu.tr, https://orcid.org/0000-0002-9673-5604

${ }^{4}$ Doç. Dr., Afyon Kocatepe Üniversitesi/Turizm Fakültesi/Gastronomi ve Mutfak Sanatları Bölümü/ Gastronomi ve Mutfak Sanatları Anabilim Dalı, sandikcimustafa@ hotmail.com, https://orcid.org/0000-0002-1437-2484
} 


\section{EXTENDED ABSTRACT}

\section{Introduction}

While food and drink were consumed in order to survive in the early ages, they have recently been associated with values such as unity, status, and gaining prestige (Yazit, 2021: 46). With this prestige obtained by food and beverage, eating and drinking become the subject of scientific activities under the name of gastronomy (Uyar \& Zengin, 2005: 355) and they have an important interaction with culture (Aksoy, 2015). The interaction of gastronomy with culture is essential in the emergence and development of gastronomy tourism. Within the scope of gastronomic tourism, tourists participate in the travel activities in order to taste and experience the local foods, beverages, and other gastronomic elements (Çağl1, 2012: 41) and these activities are increasing day by day. However, the historical and cultural assets in a place are also important for the development of gastronomic tourism (Pamukçu et al., 2021). Afyonkarahisar has an important tourism potential in terms of its historical and natural beauties (Aydın, 2015). Especially, tourists, who visit the castle, go to the city centre by the route where the historical mansions are located. Tourists can experience traditional dishes in the mansions in this region (Özdemir \& Kervankıran, 2012). In this direction, the aim of the research is to determine the effects of historical mansions that serve local foods in Afyonkarahisar on the development of gastronomic tourism.

\section{Literature review}

Gastronomy tourism is defined as eating the food of well-known restaurants, experiencing the food of the region, getting to know the tools and equipment in the kitchen, and having information about the local cuisine culture (Dağ, 2000). According to another definition, gastronomic tourism is expressed as a type of tourism that creates an important travel desire to gain new experiences in the field of food and beverage and greatly affects travel behaviors (Harrington \& Ottenbacher, 2010). The first condition sought in gastronomic tourism is that the tourists, who visit any region, regardless of their purpose, consume food and beverage in any business during tourism activities. Being in one or several parts of the process from the field to the table of food and beverages and being interested in this area are considered as other important conditions for the realization of gastronomy tourism (Sarışı \& Özbay, 2015: 275). Based on these conditions, Sarışık and Özbay (2015) summarize the definitions of gastronomy tourism with three basic elements. These are as follows:

- Experiencing different foods and beverages and seeing the production phase,

- Learning about different cultures and traditions by observing,

- Discovering new food and ways of eating.

Local foods are very important in gastronomic tourism. It is possible to reach local cuisine in many cities in Turkey. Afyonkarahisar, which is one of them, has a rich variety in terms of its cuisine and traditional flavors (Aydın, 2015). Afyonkarahisar's cuisine, meat and meat products, pastries, cream, Turkish delight, and poppy are consumed depending on agricultural products and livestock. (Kizildemir, 2019). However, Afyonkarahisar is an important tourism city with its historical attractions. One of the historical attractions is its mansions.

Historical mansions of Afyonkarahisar are widely available in the city centre and their districts. They have their own neighborhoods, streets, and residences. The building materials of the mansions generally consist of wood and adobe. The facade architecture of these mansions, which are in the old city texture, being two or three floors and being arranged side by side, are conducive to the formation of a unique structure (Kunduracı \& Bahargülü, 2018). It is known that the historical mansions, which are densely located around the castle in the city centre, were the first settlements. It is also possible to find traces of the Hittite, Phrygian, Seljuk, and Ottoman Empires in this region. Visitors, who go up to Afyon Castle, also visit historical mansions while heading towards the city centre. The mansions (Mihrioğlu Mansion, Mevlevi Mansion, Kale Mansion, Kadınana Mansion, Bey Mansion) in this area have been opened to tourism and the visitors are resting and consuming foods peculiar to the Afyonkarahisar region (Özdemir \& Kervankiran, 2012). 


\section{Methodology}

Historical mansions in Afyonkarahisar were selected as the application area in the research, and the data were obtained from historical mansion managers and employers. The fact that Afyonkarahisar is a gastro-city and that its local foods are served in the historical mansions is the main reason why the population consists of managers and employers in these mansions. In the research, the qualitative data collection method was applied and interview technique was preferred. The interviews were held between 25.04.2021 and 15.05.2021. The data were obtained with a semi-structured interview form. The obtained data were analyzed by the content analysis technique.

\section{Findings and discussion}

In the research, the importance of historical mansions in the development of gastronomic tourism has been tried to be determined. In this direction, it has been identified that local foods have reached a standard, and in order to ensure their sustainability, employees are taught about its production and information about its history. According to the findings that were obtained in the research, $90 \%$ of fresh products are used in the production of foods. However, the tools used in food making are exhibited and information about its history is presented. However, according to the participants, historical-cultural assets and elements are more effective than local foods in the realization of travels to Afyonkarahisar. Historical mansions are one of these assets. According to the research, 23 local foods are served in these historical mansions.

\section{Results and recommendations}

According to the results obtained from the research, the fact that the enterprises generally use fresh products and display their kitchen equipment shows that the historical mansions in Afyonkarahisar can carry the culinary culture of the region to the present day. However, customers generally do not prefer historical mansions for their food, but they use them to meet their food and beverage needs when they visit the buildings, museums, and castles in the region. In this direction, it can be stated that historical mansions are very important in terms of trying local flavors and making significant contributions to the development of gastronomic tourism. According to the findings, 23 local dishes of Afyonkarahisar are sold in historical mansion businesses. This is very important in terms of both promoting local dishes and enabling tourists to experience these flavors and having information about their culture. In general, it can be observed that historical mansions have a mission to reflect the Afyonkarahisar culture to tourists as well as its trade. It is thought that these mansions, which serve sincerely and friendly, can be evaluated within the scope of gastronomic tourism according to the research results. However, it is observed that promotional activities are insufficient. For this reason, it can be suggested that the host manageremployer and supply determinants focus on promotion and advertising activities in the applied field. 


\section{Giriş}

Yiyecek ve içecek; ilk çağlarda hayatta kalabilmek için tüketilirken son zamanlarda birliktelik, statü ve saygınlık kazanmak gibi değerlerle ilişkilendirilmektedir (Yazıt, 2021: 46). Yiyecek ve içeceğin kazandığ 1 bu itibar ile yeme-içme gastronomi adı altında bilimsel faaliyetlerin konusunu da oluşturmaktadır (Uyar ve Zengin, 2005: 355). Gastronomi ise antropoloji, beslenme, çevre-bilim, ekonomi, gıda, kimya, sosyoloji, tıp bilimleri, toplum, ziraat ve daha birçok kavram ile etkileşim içerisindedir (Scarpato, 2001; Göker, 2011). Gastronominin etkileşim içerisinde olduğu kavramlardan biri de kültürdür (Aksoy, 2015). Gastronominin kültür ile etkileşim halinde olması ise gastronomi turizminin ortaya çıkmasında ve gelişmesinde oldukça önemlidir. Zira literatürde kültürün (Wilson vd., 2001; Alinejad ve Razaghi, 2012; Göğebakan, 2015; Sezer, 2017; García-Hernández vd., 2017; Saraç ve Tanrısever, 2018) ve kültür ögelerini bünyesinde barındıran yöresel yiyeceklerin (Ryu ve Jang, 2006; Peštek ve Činjarević, 2014; Alderighi, Bianchi, ve Lorenzini, 2016, Pamukçu vd., 2021) turizmin gelişmesi üzerinde etkisini ortaya koyan çok sayıda çalışma bulunmaktadır.

Kültür ve yiyecekler ile harmanlanan gastronomi turizmi; tanınmış restoranların yemeklerini yemek, bölgeye ait yiyeceği deneyimlemek ve mutfak kültürü hakkında bilgi sahibi olmak şeklinde tanımlanmaktadır (Dağ, 2000). Bir başka tanıma göre gastronomi turizmi, yiyecek ve içecek alanında yeni deneyimler kazanmak üzere ortaya çıkan seyahat isteği ve davranışı olarak ifade edilmektedir (Harrington ve Ottenbacher, 2010). Turistler, gastronomi turizmi kapsamında bir bölgenin içinde var olan o yöreye özgü yiyecekleri, içecekleri ve diğer gastronomi unsurlarını tatmak ve tecrübe etmek amacıyla seyahat faaliyetlerine katılmakta (Çağl1, 2012: 41) ve bu faaliyetler her geçen gün artış göstermektedir. TÜRSAB, 2014 yılında bir gastronomi turizm raporu hazırlamıştır. Bu rapora göre dünyada turist sayısı 1 milyara ulaşmıştır. Bu turistlerin yüzde 88,2'si ise "destinasyon tercih etmede yemek çok önemli” ifadesini kullanmaktadır.

Gastronomi turizmi Türkiye'de de oldukça önemlidir. Zira Türkiye'ye gelen turistlerin harcamalarının \%19'u yeme içme amaçlı gerçekleşmektedir (TÜRSAB, 2014). Bu doğrultuda Türkiye'deki birçok ilde gastronomi faaliyetleri artış göstermektedir. Bu illerden biri de Afyonkarahisar'dır. Afyonkarahisar, Anadolu mutfak kültürünü yansıtan (Kızıldemir, 2019: 648) tarım ve hayvancılık ile uğraşan (Sandıkçı ve Özkan, 2017: 852) zengin mutfak içeriğine sahip bir ildir (Gülen, 2017: 40). Diğer yandan 2019 yılında Yaratıcı Şehirler Ağına katılarak Türkiye'deki üç gastronomi şehrinden biri olmuştur. Bu nedenle ileride gastronomi turlarında ve gastronomiye yönelik akademik yazında rotanın Afyonkarahisar'a çevrileceği ve bu ilin önemli bir gastronomi kenti olacağı düşünülmektedir (Sandıkçı, Mutlu ve Mutlu, 2020: 2530). Ancak bugün Afyonkarahisar'in tercih edilmesindeki ana motivasyon kaynağı termallerdir.

Termal turizm kaynaklarının yanı sıra Afyonkarahisar, önemli tarihi ve doğal çekiciliklere de sahiptir (Aydın, 2015). Bu çekiciliklerden birisi de tarihi konaklardır. Özellikle kaleyi ziyaret eden turistler, şehir merkezine tarihi konakların olduğu güzergahtan gitmektedir. Bu bölgede bulunan konaklarda turistler geleneksel yemekleri deneyimleyebilmektedir (Özdemir ve Kervankıran, 2012). Bu da tarihi değerlerin ve yapıların, gastronomi turizmi gelişimine önemli düzeyde katkı sağladığı anlamına gelmektedir. Pamukçu vd. (2021) araştırmasında elde etmiş oldukları sonuçlarla bu düşünceyi desteklemektedirler. Yazarlar araştırmalarında gastronomi turizminin gelişmesinde etkili faktörlere ulaşmaya çalışmışlardır. Elde ettikleri sonuçlara göre yöresel yiyeceklerin gastronomi turizmi gelişimi üzerindeki etkilerinin \%37, tarihi değer ve kültürel unsurların etkilerinin ise $\% 60$ olduğu sonucuna ulaşmışlardır. Bu nedenle Afyonkarahisar'ın bir gastronomi turizm destinasyonu olabilmesi için sahip olduğu tarihi ve kültürel zenginliğin de iyi tanıtılması ve pazarlanması gerekmektedir (Zengin ve Gürkan, 2019: 236).

Literatüre bakıldığında kültürel varlıkların gastronomi turizmi ile ilişkisinin incelendiği çok sayıda çalışmaya rastlanmaktadır (Hall vd., 2003; Kivela ve Crotts, 2006; Durlu vd., 2013; Gülen, 2017). Birdir ve Akgöl (2015) araştırmasında, Türkiye'yi ziyaret eden turistlerin yöresel yiyecekleri genellikle yöresel yemek sunan işletmelerde tüketmek istediğini belirtmiştir. Ayyıldız ve Kargıglıŏlu (2018) araştırmalarında ise Safranbolu konaklarında sunulan yöresel yemeklerin turizme olumlu katkıda bulunduğunu ortaya koymuşlardır. 
$\mathrm{Bu}$ araştırmada ise Afyonkarahisar'da yöresel yemek sunan tarihi konakların gastronomi turizminin gelişmesi üzerindeki etkileri araştırılmaktadır. Araştırmada uygulamalı alan olarak Afyonkarahisar'ın tercih edilmesinin en önemli nedeni kentin UNESCO Yaratıcı Gastronomi Şehri ünvanına sahip olmasıdır (Creative Cities Network, t.y). Tarihi konakların tercih edilmesinin nedeni ise yöresel yiyeceklerin sunulması ve bu konakların önemli kültür değerlerini bünyelerinde barındıran taşınmaz sivil mimari örneklerine sahip olmalarıdır (Tanrısever vd., 2016). Bu doğrultuda gastronomi turizmi motivasyonunun belirlenmesinde tarihi ve kültürel değerlerin öneminin sorgulanması literatüre katk1 sağlayabilecektir. Diğer yandan araştırma, uygulamalı alanda gastronomi turizminin gelişmesine yönelik izlenecek strateji ve politikalara yönelik fikir verebilir.

\section{Literatür taraması}

Gastronomi kelimesi iki yüz yıl önce Jacques Berchoux (1804) tarafından yayınlanan bir şiir başlığı olarak kullanılmıştır (Scarpato, 2001: 51). Günümüzde ise besinle alakalı açıklamalı bilgiler sunan bir bilimdir (Uyar ve Zengin, 2005: 355; Savarin, 2015: 53). Bu açıklamalar; gıdanın üretimi, işlenmesi, depolanması, taşınması, pişirilmesi ve gıda üretimi sürecinde kullanılan araç, gereç, gelenek ve görenekleri kapsamaktadır (Scarpato, 2001: 51). Yiyecek içecek işletmelerinin turizmin önemli dört temel direğinden biri olması gastronominin turizm içerisinde yer bulmasına neden olmaktadır. $\mathrm{Bu}$ kapsamda oluşan gastronomi turizmi, insanların yaşadıkları yerlerden değişik yiyecek içecek kültürlerine sahip bölgelere seyahatler gerçekleştirerek, o alanda bulunan kültürü ve mutfak deneyimini yaşama imkânı sunmaktadır (Kaya, 2021: 215). Gastronomi, turizmin gelişmesine de oldukça önemli katkılar sunmaktadır (Aksoy ve Sezgi, 2015: 80). Zira yeme-içme günümüzde temel ihtiyaçların karşılanmasından ziyade birçok sektörü etkileyen ekonomik etkinlik olarak görülmektedir (Şeker ve Hastaoğlu, 2020: 1879). Bu etkinliklerden biri olan gastronomi turizminde aranan ilk şart; amacı ne olursa olsun destinasyon ziyaretinde bulunan turistlerin turizm faaliyetleri esnasinda herhangi bir işletmede yiyecek ve içecek tüketimi gerçekleştirmeleridir. Diğer önemli bir şart ise turistlerin yiyecek ve içeceklerin tarladan sofraya gelene dek gerçekleşen aşamaların bir ya da birkaçında yer almaları ve bu alana ilgi duymalarıdır (Sarışık ve Özbay, 2015: 275). Bu şartlardan yola çıkarak Sarışık ve Özbay (2015) gastronomi turizm tanımlarını üç temel unsur ile özetlemektedir. Bunlar:

- Farklı yiyecek ve içecekleri deneyimleme ve üretim aşamasını görme,

- Farklı kültürleri ve gelenekleri gözlem yaparak öğrenme,

- Yeni bir yemeği ve yeme şekillerini keşfetme.

Gastronomi turizminin, uluslararası turizmde uygulamalarına bakıldığında; Fransa, İtalya, İspanya, Tayland ve Çin gibi ülkelerin kendi yerel mutfaklarına olan ilgisi ile kalkınmışlık düzeylerinin paralellik gösterdiği görülmektedir (Ballı, 2016: 8). Zira yörelerin kültürel mirasından olan yöresel mutfaklarına sahip çıkması çok önemlidir. Türkiye bu anlamda çok zengin ve avantajı bir konumdadır (Yazıt, 2021: 48). Türkiye dünyada ve Avrupa'da gastronomi turizmi bakımından en önemli destinasyonlardan biri olarak görülmektedir (Işkın, 2021: 32). Birdir ve Akgöl (2015) çalışmalarında Türkiye'ye gelen turistlerin ziyaret etme nedenlerini araştırmışlardır. Çalışma sonuçlarına göre turistlerin Türkiye'yi ziyaret etmelerindeki ana motivasyon Türkiye tarihi ve doğal güzellikleridir. Diğer seyahat etme motivasyonları ise sırasıyla Türk halkını tanıma ve Türk mutfağına özgü yöresel yiyecekleri tatmadır. Yöresel yiyecekler ve mutfaklar, kültürlerin en seçkin örneklerini yansıtmaktadır. Bu bakımdan yapı taşı kültür olan turizm ve yöresel mutfak arasında yakın bir ilişki bulunmaktadır (Zengin ve Işsın, 2017: 412).

Yöresel mutfak; ürünün coğrafi olarak işaretlenmesi, o yörenin kültüründen özgün izler taşıması, yöreye özgü ürünlerin o yöredeki adetlerle bütünleşmesi olarak tanımlanmaktadır. Bir başka anlatımla yöresel mutfak yörenin pişirme teknikleri ve pişirme araç-gereçlerinin kullanılması, dini ya da milli nedenler ile halkın üstün tuttuğu yemekler ve içeceklerin tamamı olarak ifade edilmektedir (Şengül ve Türkay, 2016: 91). Bahsi geçen anlatımlar, turizm faaliyetlerinde çok önemli bir etkiye sahip olan çekicilik unsuru olarak ele alınmaktadır. Türkiye'de birçok ilde yöresel mutfağa ulaşmak mümkündür. Bunlardan biri olan Afyonkarahisar mutfağı, geleneksel lezzetleri bakımından zengin bir çeşitliliğe sahiptir (Aydın, 2015). Afyonkarahisar mutfağında tarım ürünleri ve hayvancıllğa bağlı olarak et ve et ürünleri, hamur işleri, kaymak, lokum ve haşhaş gibi yiyecekler tüketilmektedir (Kızıldemir, 2019). Diğer yandan 
Afyonkarahisar'ın tarihi ve doğal çekicilikleriyle turizm açısından oldukça önemli bir kent olduğunu da söylemek mümkündür. Afyonkarahisar'ın önemli tarihi varlıklarından biri de konaklardır.

Tarihi Afyonkarahisar konakları, şehir merkezi ve ilçelerinde yaygın bir şekilde bulunmaktadır. Kendine has mahalle, sokak ve meskenleri bulunur. Konakların yapı malzemesi genel olarak ahşap ve kerpiçtir. Eski kent dokusu içerisinde kalan bu konakların sahip olduğu cephe mimarisi, iki - üç katlı olması ve yan yana dizilmesi, kendine özgü bir yapının oluşmasına vesile olmaktadır (Kunduracı ve Bahargülü, 2018). Şehir merkezinde olan kale çevresinde yoğun olarak bulunan tarihi konakların ilk yerleşim yeri olduğu bilinmektedir. Zira bu bölgede Hitit, Firig, Selçuklular ve Osmanlı İmparatorluğunun izlerine rastlamak da mümkündür. Afyon Kalesi'ne çıkan ziyaretçiler şehir merkezine doğru inerken tarihi konakları da ziyaret etmektedir. Bu alanda bulunan konaklar (Mihrioğlu konağı, Mevlevi konağı, Kale konak, Kadınana konağı, Bey konağı) turizme açılmış ve gelen ziyaretçiler dinlenerek, Afyonkarahisar yöresine özgü yiyecekleri tüketmektedir (Özdemir ve Kervankıran, 2012). Türk kültürünü çok iyi şekilde yansitan sivil mimari örneklerinden biri olan tarihi konaklar, Türk toplumunun gelecek nesillere aktardığı, gelenek ve göreneklerin yaşatıldığı yapı türleridir (Beyazıt, 2009: 681). Türkiye'de bulunan çok sayıda tarihi kent merkezi ve bu merkezlerde yer alan geleneksel evler, kültürel bilincin yükselmesi ile beraber koruma altına alınıp günün şartlarına göre yeniden işlevlendirilmektedir (Kocaman, Kayserili ve Kaya, 2014: 149; Tanrısever vd., 2016; Saraç ve Tanrısever, 2018). Tarihi konak işletmeleri, butik otel tasarımları ile kişiye özel hizmet sunabilmesi ve büyük ölçekli otel işletmelerinin yoğunluklarından dolayı alternatif olarak hizmet sunan işletmelerdir (Yücel ve Bayhan, 2017: 433). Yiyecek içecek işletmesi olarak işlevlendirilen tarihi konaklar da mevcuttur. Bu konaklar kültürün geleceğe aktarılmasını sağlamakta ve önemli bir çekicilik unsuru oluşturmaktadır (Saraç ve Tanrısever, 2018: 154). Bu nedenle burada servis edilecek yöresel yiyeceklerin varllğ 1 korunurken konakların sahip olduğu çekicilik de artmaktadır.

\section{Yöntem}

$\mathrm{Bu}$ araştırmanın amacı, Afyonkarahisar'da yer alan tarihi konakların gastronomi turizminin gelişimi açısından taşıdığı önemin belirlenmesidir. Araştırmanın bir diğer amacı ise tarihi konaklarda sunumu yapılan geleneksel yemeklerin neler olduklarının tespit edilmesidir. Diğer yandan araştırmada turistlerin gastronomi turizminde önceliklerinin neler olduğunun tespit edilmesi de amaçlanmaktadır.

Araştırmada uygulama alanı olarak Afyonkarahisar'da bulunan tarihi konaklar seçilmiş veriler tarihi konak yönetici ve işverenlerinden elde edilmiştir. Afyonkarahisar'ın bir gastro kent olması ve tarihi konaklarda yöresel yiyeceklerin servis edilmesi ana kütlenin bu konaklardaki yönetici ve işverenlerden oluşmasının en temel nedenidir. Araştırmada, nitel veri toplama yöntemine başvurulmuş ve görüşme tekniği tercih edilmiştir. Görüşmeler 25.04.2021 ile 15.05.2021 tarihleri arasında gerçekleştirilmiştir. Görüşme tekniği, önceden hazırlanmış olan soruların katılımcılara yöneltilmesi ve katılımcıdan cevap alınması üzerine kurulmuş bir söyleşi olarak tanımlanmaktadır (Kuş, 2003). Bu araştırmada görüşme tekniğinin tercih edilmesinin en önemli nedeni bu tekniğin araştırılan konuda derinlemesine soru sorulabilmesi ve istenilen nitelikte cevap alıncaya değin soru sormaya imkân tanımasıdır (Çepni, 2009).

Afyonkarahisar merkezinde toplamda yedi adet tarihi konak bulunmaktadır. İki konak kapalı olduğu için bu konaklarla iletişim kurulamamıştır. Bu nedenle görüşme beş tarihi konak (Mihrioğlu Konağ1, Mevlevi Konağı, Bey Konağı, Kale Konak ve Kadınana Konağı) yönetici ve işvereni ile yapılmıştır. Görüşmede katılımcılardan izin alınarak ses kaydı alınmıştır. Veriler görüşme formu ile elde edilmiştir. Görüşme formunda iki bölüm yer almaktadır. Formun ilk bölümünde demografik özelliklerin belirlenebilmesi için altı soru sorulmuştur. İkinci bölümde ise gastronomi turizmi ile ilgili sekiz soru yer almaktadır. Bu soruların hazırlanmasında; Sparks vd., 2003; Moria vd., 2015; Sandıkçı vd., 2015; Şengül ve Türkay, 2016; Ören ve Ören, 2019 çalışmalarından istifade edilmiştir. Veriler içerik analizi tekniği ile analiz edilmiştir. İçerik analizi; bir metnin belirli kurallara dayalı olarak daha küçük içerik kategorileri halinde kodlanarak özetlenmesini sağlayan sistematik ve yinelenebilen bir tekniktir (Büyüköztürk vd., 2010: 269). İçerik analizi yöntemi hem nitel hem de nicel çalışmalarda kullanılmakta belirlenmiş bir konu veya birbirinden farklı konuların derinlemesine incelenip düzenlenmesini sağlamaktadır. Bu analiz yardımıyla veriler niceliksel olarak incelenebilmektedir (Ültay, Akyurt ve Ültay, 2021: 189). Bu doğrultuda araştırmada sorulara verilen cevaplar içeriklere göre 
sınıflandırılmıştır. Verilen cevaplar tablolaştırılmış ve katılımcılara numara verilmiştir. Farklı yanıtlara tabloda bağımsız olarak yer verilirken birbirine eşdeğer olduğu kabul edilen yanıtlar özetlenerek birlikte değerlendirilmiştir. Cevaplar, katılımcı numaraları ve sayılarına göre tabloya eklenmiş ve belirtilmiştir.

\section{Bulgular ve tartışma}

Tablo 1'de araştırmada uygulama alanı olarak tercih edilen tarihi konaklar hakkında bilgi verilmiştir. Görüldüğü üzere beş tarihi konak işletmesi 110 ile 120 yıl önce inşa edilmiş ve 5 - 15 yıldır hizmet vermektedir. Bu konaklar restoran olarak işlev kazanmakta müze ve hediyelik eşya satma işlevlerini yürüten konaklar da bulunmaktadır. Konakların bir kısmı sahipleri bir kısmı ise yöneticiler tarafından işletilmektedir.

Tablo 1: Tarihi konak bilgileri

\begin{tabular}{|c|c|c|c|c|c|c|c|}
\hline $\begin{array}{l}\text { Sira } \\
\text { No }\end{array}$ & Yapı Adı & Yapı Görseli & $\begin{array}{l}\text { Görüşme Yapılan } \\
\text { Yönetici/İşveren }\end{array}$ & $\begin{array}{l}\text { Eski } \\
\text { İşlevi }\end{array}$ & $\begin{array}{l}\text { İnşaat } \\
\text { Tarihi }\end{array}$ & $\begin{array}{l}\text { Mevcut } \\
\text { İşlevi }\end{array}$ & $\begin{array}{l}\text { Yeni İşlev } \\
\text { Tarihi }\end{array}$ \\
\hline 1 & $\begin{array}{l}\text { Mihrioğlu } \\
\text { Konağ } 1\end{array}$ & & Yönetici & Konak & 1905 & Restoran & 2006 \\
\hline 2 & $\begin{array}{c}\text { Mevlevi } \\
\text { Konağ } 1 \\
\end{array}$ & & İşveren & Konak & 1905 & $\begin{array}{l}\text { Müze/ } \\
\text { Restoran }\end{array}$ & 2008 \\
\hline 3 & Bey Konağı & & Yönetici & Konak & 1904 & Restoran & 2017 \\
\hline 4 & Kale Konağ & & İşveren & Konak & 1901 & $\begin{array}{l}\text { Hediyelik } \\
\text { eşya/ } \\
\text { Restoran }\end{array}$ & 2013 \\
\hline 5 & $\begin{array}{l}\text { Kadınana } \\
\text { Konağ } 1\end{array}$ & & İşveren & Konak & 1908 & Restoran & 2011 \\
\hline
\end{tabular}

Tablo 2'de tarihi konakları temsil eden yönetici ve işverenlerin demografik bilgilerine yer verilmiştir. Tablo 2'ye göre katılımcıların büyük bir çoğunluğu erkektir. Yaşlarına bakıldığında yöneticilerin genç, işverenlerin ise orta ve üçüncü yaş grubuna ait olduğu görülmektedir. Konaklardaki çalışma süreleri ise 4-15 y1l arasında değişiklik göstermektedir. Katılımcıların hepsi Afyonkarahisar'ın yerlisidir ve turizmden farklı bölümlerde eğitim almışlardır.

Tablo 2: Katılımcıların demografik özellikleri

\begin{tabular}{|c|c|c|c|c|c|c|}
\hline Katılımeı & Cinsiyet & "Yaş & Sektör Deneyimi & " Mezun Olunan Bölüm & "Memleket & Unvan \\
\hline 1 & Erkek & 28 & 14 y1l & Otomasyon & Afyonkarahisar & Yönetici \\
\hline 2 & Kadın & 45 & $12 \mathrm{y} 11$ & Maliye & Afyonkarahisar & İşveren \\
\hline 3 & Erkek & 20 & 4 y1l & Uçak bakım & Afyonkarahisar & Yönetici \\
\hline 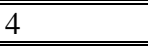 & Erkek & 65 & 8 y1l & 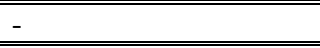 & Afyonkarahisar & İşveren \\
\hline$\overline{5}$ & Erkek & 55 & $15 \mathrm{y} 11$ & Almanca öğretmenliği & Afyonkarahisar & İşveren \\
\hline
\end{tabular}

Tablo 3'te katılımcıların gastronomi turizmine yönelik görüşlerine ve tarihi konakların gastronomi turizmi gelişimindeki etkisine ilişkin değerlendirmelerine yer verilmiştir. Bu görüş ve değerlendirmelere göre;

Katılımcılar konaklarında servis ettikleri yöresel yiyeceklerin bir standardının oluştuğunu ve gelen müşterilerin yiyecek hususunda herhangi bir sürprizle karşılaşmadıklarını, yiyeceklerin lezzetinden memnun kaldıklarını, konaklardaki yöresel yiyecekleri bu nedenle tercih ettiklerini belirtmişlerdir. Katılımcıların diğer bir kısmı yemeklerde Afyonkarahisar'ın kültürünü yansıtabildiklerini ve başka işletmelerde bu tür hizmet verilemediğinden müşterilerin buradaki yöresel yiyeceklere ilgi duyduğunu 
belirtmiştir. Diğer yandan katılımcılara göre Afyonkarahisar'a yönelik seyahatlerin gerçekleşmesinde yöresel yiyeceklerden ziyade tarihi konaklar, Sultan divani müzesi, Mevlevihane müzesi, Ulu Cami ve Afyon kalesi gibi tarihi- kültürel varlık ve unsurlar etkilidir.

Katılımcılar konaklarda \%90 oranında taze ürün kullanımı olduğunu belirtmiştir. Mutfak araç-gereç kullanımında bazı katılımcılar hijyen mefhumunu öne sürerek müşterilerin bu tür bir kullanımına müsaade etmediklerini belirtmiştir. Bir diğer katılımcı grubu ise mutfağın kapılarının müşterilere her zaman açık olduğunu ifade etmiştir. Yapılan görüşmede mutfağa ait yöresel araç ve gereçlerin tanıtımı ve gösteriminin ise tüm katılımcılar tarafından hassasiyetle gerçekleştirildiği sonucuna ulaşılmıştır.

Tablo 3: Araştırmaya katılan işveren/yöneticilerin gastronomi turizmine yönelik görüşleri

\begin{tabular}{|c|c|c|c|}
\hline 1 & $\begin{array}{l}\text { İşletmenizdeki Afyonkarahisar yöresel ürünlerini müşterilerinizin tercih etme sebebi } \\
\text { nedir? }\end{array}$ & $\begin{array}{l}\text { Katılımeı } \\
\text { Sayısı }\end{array}$ & $\begin{array}{l}\text { Katılımeı } \\
\text { Numarası } \\
\end{array}$ \\
\hline & $\begin{array}{l}\text { Ev yemekleri ve yöresel yemeklerimizin lezzeti ve tat ve lezzetin devamlı olarak aynı şekilde } \\
\text { olması }\end{array}$ & 2 & $1+1,4$ \\
\hline & Afyon kültürünü yemeklere yansıttık ve menümüzü ona göre oluşturmamızdan dolayı & 2 & 2,5 \\
\hline & Müşterinin bu civarda yöresel yemek yiyeceği yer olmamasından dolayı & 1 & 3 \\
\hline \multirow[t]{2}{*}{2} & Menülerinizde bulunan yiyeceklerde taze ve mevsimlik ürün kullanım oranı nedir? & & \\
\hline & Dondurulmuş ürün kullanmıyoruz \%90 taze ürün kullanıyoruz & 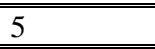 & $1,2,3,4,5$ \\
\hline \multirow[t]{4}{*}{ 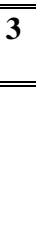 } & $\begin{array}{l}\text { Turistlerin bölgeyi tercih etmesinde yöresel lezzetlerin önemi hakkında düşünceniz } \\
\text { nedir? }\end{array}$ & & \\
\hline & "Konaklar, kültürü yansıttığından dolayı müşteriler yemeklerini burada yemek istiyor & 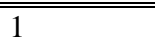 & 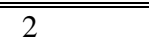 \\
\hline & Yöresel lezzetlerin önemi yoktur, kalesinden dolayı geliyorlar & 1 & 3 \\
\hline & $\begin{array}{l}\text { Sultan divani müzesi, Mevlevihane müzesi, ulu cami, afyon kalesi ve tarihi konakların } \\
\text { olmasından dolayı müşteriler tercih ediyor }\end{array}$ & 3 & $1,4,5$ \\
\hline \multirow[t]{2}{*}{4} & $\begin{array}{l}\text { İ́şletmenizde, mutfağa ait folklorik (yöresel) araç ve gereçlerin tanıtımı için gelen } \\
\text { misafirlere anlatım ve gösterim sağlanması hakkında görüşünüz nedir? }\end{array}$ & & \\
\hline & $\begin{array}{l}\text { Evet, Afyonkarahisar mutfağına ait folklorik araç ve gereçlerin tanıtımını yapıyoruz ve } \\
\text { sergiliyoruz }\end{array}$ & 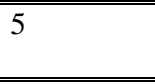 & $1,2,3,4,5$ \\
\hline \multirow[t]{3}{*}{5} & $\begin{array}{l}\text { Müşterinin işletmenizdeki mutfak araçlarını kullanarak Afyonkarahisar'ın yöresel } \\
\text { lezzetlerini deneyimleyebilmesi hakkında ne düşünüyorsunuz? }\end{array}$ & & \\
\hline & $\begin{array}{l}\text { Müşterilerimize mutfak araçlarını kullanması için izin vermiyoruz ama fotoğraf çekmesini } \\
\text { ve tadım yapmasını söylüyoruz }\end{array}$ & 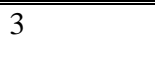 & $1,2,3$ \\
\hline & $\begin{array}{l}\text { Mutfağımızın kapısı her zaman açıktır, gelen müşterilerimiz isterse kendi ürünlerini } \\
\text { kendileri yapabilirler }\end{array}$ & 2 & 4,5 \\
\hline \multirow[t]{3}{*}{ "6 } & $\begin{array}{l}\text { Müşterilerinize, Afyonkarahisar yöresel ürünlerin tarihi hakkında ne tür bilgiler } \\
\text { veriyorsunuz? }\end{array}$ & & \\
\hline & "Vermiyoruz, fakat ben konuya hâkimim & 1 & 3 \\
\hline & $\begin{array}{l}\text { Afyonkarahisar'da bulunan yöresel ürünlerin tanıtımı yapılıyor. Yiyeceklerin geçmişlerini } \\
\text { söylüyoruz. Örnek olacaksa göce köttüsü }\end{array}$ & 4 & $1,2,4,5$ \\
\hline \multirow[t]{3}{*}{ 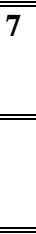 } & $\begin{array}{l}\text { İşletmenizde bulunan gastronomi ürünlerinin zenginleştirilmesi, aslına uygun bir } \\
\text { şekilde sunulması, pazarlanması ve nihayetinde gelecek nesillere aktarılmasında sizin } \\
\text { rolünüz nedir? }\end{array}$ & & \\
\hline & $\begin{array}{l}\text { Biz, elemanlarımıza ve müşterilerimize } \\
\text { politikayı gösteriğımır ve öğretiyoruz }\end{array}$ & 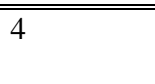 & $1,2,4,5$ \\
\hline & Şuan bir çalışmamız yok, fakat ilerleyen zamanlarda bunun için çabalayacağız & 1 & 3 \\
\hline \multirow[t]{6}{*}{ 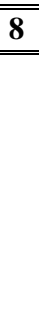 } & İşletmenizde Afyonkarahisar’a özgü hangi yiyeceklerin sunumunu yapıyorsunuz? & & \\
\hline & $\begin{array}{l}\text { Etli yaprak sarma, Musakka, Patlıcan böreği, Afyon kebabı, Ekmek kadayıfı, Tandır çorbası, } \\
\text { Tarhana çorbası, Afyon kebabı, Mantı, Bamya, Manda yoğurdu }\end{array}$ & 1 & 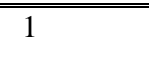 \\
\hline & $\begin{array}{l}\text { Keşkek, Mantı, Ağzı açık, Bükme, Katmer, Mevlevi şerbeti, Tarhana çorbası, Ekmek } \\
\text { kadayıfı, Kabak Tatlısı }\end{array}$ & 1 & 2 \\
\hline & Kahvaltı, Bükme, Sacda sucuk, Küp keşkek, Sobada patates, Kaymak, & 1 & 3 \\
\hline & Katmer, Kahvaltı, Gözleme, Kaygana, Cimcik hamur aşı, velemse & 1 & 4 \\
\hline & Göce köttüsü, ağzı açık, Bükme, Yaprak sarma, Afyon kebabı, Lokum(ikram), Ekmek & 1 & 5 \\
\hline
\end{tabular}
kadayifi

$\overline{\text { Katılımcılar, müşterilere Afyonkarahisar yöresel ürünlerinin tanıtımını yaptıklarını ve tarihi hakkında }}$ bilgiler verdiklerini belirtmişlerdir. Kültürel sürdürülebilirliğin sağlanmasında ise yiyeceklerin yapımını çalışanlarına gösterdiklerini ve izledikleri politikalar hakkında çalışanlarını bildirdiklerini ifade etmişlerdir. 
Katılımcıların verdiği cevaplara göre tarihi konaklarda 23 farklı yöresel ürünün sunumunu gerçekleşmektedir. Bunlar; Etli yaprak sarma, Musakka, Patlıcan böreği, Afyon kebabı, Ekmek kadayıfı, Tandır çorbası, Tarhana çorbası, Afyon kebabı, Mantı, Bamya, Manda yoğurdu, Keşkek, Ağzı açık, Bükme, Katmer, Mevlevi şerbeti, Kabak Tatlısı, Gözleme, Kaygana, Cimcik hamur aşı, Velemse, Göce köttüsü ve Lokumdur.

\section{Sonuç ve öneriler}

$\mathrm{Bu}$ araştırmada Afyonkarahisar'da bulunan tarihi konakların gastronomi turizmi açısından önemi konak temsilcileriyle yapılan görüşme sonrasında belirlenmiş ve konaklarda servis edilen yöresel yiyecekler tespit edilmiştir. Erdem, Mızrak ve Kemer (2018) çalışmalarında Bolu ilindeki Mengen'in bölge restoranlarında yöresel yemeklerin kullanıldığını belirleyerek benzer bir sonuca ulaşmışlardır. Ancak yiyecek içecek işletmelerinin mönülerinde yöresel yiyecek kullanımının belirlenmesine yönelik bazı çalışmalarda farklı sonuçlara ulaşılmıştır. Bu çalışmalara göre; Hatipoğlu vd., (2013) Aksaray’ın Gelveri yöresindeki konakların mönülerinde yöresel yiyeceklere yer vermediklerini tespit etmişlerdir. Özleyen ve Tepeci (2017) ise çalışmalarında Manisa'daki lokanta ve otel işletmelerinin yöresel yemeklere fazla yer vermedikleri sonucuna ulaşmışlardır. Kurnaz ve İşlek (2018) çalışmalarında Marmaris'teki restoranların mönülerinde yöresel yiyeceklerin tercih edilmediği sonucuna ulaşılmıştır. Araştırmalardan yola çıkararak yöresel yiyeceklerin bazı bölgelerde yok olmaya başladığı Afyonkarahisar'da ise tarihi konakların yöresel yiyeceklerin sürdürülebilirliğinde önemli bir rol üstlendiği sonucuna ulaşılmaktadır.

Araştırmadan elde edilen sonuçlara göre; işletmelerin genellikle taze ürün kullanması, mutfak ekipmanlarını sergilemesi, tanıtması ve mutfak ekipmanlarının tarihi hakkında bilgiler sunması Afyonkarahisar'da bulunan tarihi konakların yöreye ait mutfak kültürünü günümüze taşıyabildiğini göstermektedir. Bununla birlikte turistler genel olarak tarihi konakları, yiyecekleri için tercih etmemekte, bölgede bulunan yapılar, müzeler ve kale için ziyarette bulunduklarında yeme içme ihtiyaçlarını karşılamak üzere kullanmaktadırlar. $\mathrm{Bu}$ doğrultuda birer kültürel varlık olan tarihi konakların yöresel lezzetlerin denenmesi doğrultusunda oldukça önemli olduğu ve gastronomi turizminin gelişmesine katkı sunduğu ileri sürülebilir. Yapılan birçok araştırmada kültürel varlıkların gastronomi turizmin gelişmesinde önemli rol oynadığını desteklemektedir (Hall vd., 2003; Kivela ve Crotts, 2006; Durlu vd., 2013; Başat vd., 2017; Gülen, 2017). Bu araştırmadan farklı olarak yiyecek içeceği gastronomi turizminin gelişmesinde esas alan çalışmalar da mevcuttur (Kivela ve Crotts, 2006; Du Rand, ve Heath, 2006; Sarışı ve Özbay, 2015; Alderighi, Bianchi, ve Lorenzini, 2016; Çapar ve Yenipınar, 2016; Rinaldi, 2017; Erdem, Mizrak ve Kemer, 2018; Privitera, Nedelcu ve Nicula, 2018). Pamukçu vd., (2021) ise çalışmalarında gastronomi turizmin gelişmesinde kültürel varlıkların temel unsur olduklarını yöresel mutfağın ise ikincil önemli unsur niteliği taşıdığı sonucuna ulaşmışlardır.

Çok geniş bir yiyecek yelpazesine sahip olan Afyonkarahisar'da geçmişten günümüze ulaşmış birçok yemek vardır. Fakat bu yemeklerin sunumu çok fazla restoranda yapılmamaktadır. Tarihi konaklar bu görevi başarı ile üstlenmektedir. Elde edilen bulgulara göre tarihi konak işletmelerinde 23 adet Afyonkarahisar yöresel yemeğinin satışı gerçekleştirilmektedir. Bu durum hem yöresel yemeklerin tanıtılması hem de turistlerin bu lezzetleri deneyimleyebilmesi ve kültürü hakkında bilgi sahibi olması açısından oldukça önemlidir. Zira Afyonkarahisar'ı ziyaret eden farklı kültürlere ait geniş bir turist yelpazesi bulunmaktadır. Bu turistlerin çoğunlukla geldikleri şehirler Ankara, İstanbul, İzmir, Konya, Antalya ve Aydın olarak sıralanabilmektedir (Aydın, 2015). Yurtdışından ziyaret eden turistlerin geldikleri ülkeler ise çoğunlukla Almanya, Hollanda, İsveç ve Belçika'dır. Bu ülkelerinden gelen ziyaretçilerin büyük bölümünü, bu ülkelerde yaşayan Türk vatandaşları oluşturmaktadır (Kervankıran ve Özdemir, 2013: 127).

Genel olarak tarihi konakların ticaretin yanında turistlere Afyonkarahisar kültürünü yansıtmak gibi bir misyonu olduğu da görülmektedir. Samimi ve cana yakın olarak hizmet veren bu konakların, araştırma sonuçlarına göre gastronomi turizmi kapsamında değerlendirilmelerinin mümkün olduğu düşünülmektedir. Afyonkarahisar her ne kadar termal turizm bölgesi olarak kabul edilse de (Ateş ve Başaran, 2019) 2019 yılı itibarıla Unesco Gastronomi Kenti ilan edildiğinden gastronomi turları ve akademik yazında çok daha fazla tercih edilen bir kent haline gelecektir (Sandıkçı, Mutlu ve Mutlu, 
2020: 2530). Bu nedenle uygulamalı alanda konak yönetici-işveren ve arz belirleyicilere tanıtım ve reklam faaliyetleri üzerinde durmaları önerilebilmektedir.

Sonuçta tarihi konaklar; kültür, gelenek ve göreneklerin tanıtılması açısından oldukça önemlidir. Tarihi konak işletmeleri ise kültürün ve geleneklerin deneyimlenmesini sağlamakta önemli bir rol üstlenmektedir. $\mathrm{Bu}$ araştırmada kültürel bir varlık olan tarihi konakların gastronomi turizmi gelişimi üzerindeki eksikliği ele alınarak literatüre önemli bir katkı sunulmuştur. Diğer yandan uygulamalı alanda gastronomi turizminin geliştirilmesi ve sürdürülebilirliğine yönelik oluşturulacak plan, politika ve stratejilere fikir vermesi açısından önemlidir. İleride bu konuyla alakalı çalışma yapacak araştırmacılara başka kültürel unsurlar ile gastronomi turizmi ilişkisinin belirlenebileceği araştırmalar yapması önerilebilmektedir. Diğer yandan farklı bölgelerdeki yiyecek içecek işletmelerinin menülerinde yöresel yiyeceklere yer verme durumlarını tespit etmeye yönelik araştırmalar yapılabilir.

\section{Kaynakça}

Aksoy, M. ve Sezgi, G. (2015). Gastronomi turizmi ve güneydoğu anadolu bölgesi gastronomik unsurlar1. Journal of Tourism and Gastronomy Studies, 3(3), 79-89.

Alderighi, M., Bianchi, C. ve Lorenzini, E. (2016). The impact of local food specialities on the decision to (re) visit a tourist destination: Market-expanding or business-stealing? Tourism Management, 57, 323-333.

Alinejad, M. E. ve Razaghi, Z. (2012). Culture and its role in tourism development. Life Sci. 2012 (9), 1593-1597.

Ateş, A., ve Başaran, M. (2019). Kırsal kalkınmanın sağlanmasında kadın istihdamı: Afyonkarahisar Gazlıgöl termal turizm bölgesi araştırması. Journal of Yaşar University, 14 (54), 87-95.

Aydın, E. (2015). Gastronomi Turizminin şehir markalaşmasına etkisi: Afyonkarahisar örneği. [Yüksek lisans tezi], Afyon Kocatepe Üniversitesi.

Ayyıldız, S. ve Kargıglığlu, Ş. (2018). Konaklarda sunulan yöresel yemeklerin sürdürebilirlik gastronomi turizmi bakımından incelenmesi; Safranbolu konakları örneği. Akademik Sosyal Araştırmalar Dergisi, 6 (79), 367-381.

Ballı, E. (2016). Gastronomi turizmi açısından adana sokak lezzetleri. Journal of Tourism and Gastronomy Studies, 4 (Special Issue), 3-17.

Başat, H. T., Sandıkçı, M., ve Çelik, S. (2017). Gastronomik kimlik oluşturmada yöresel ürünlerin rolü: ürünlerin satış ve pazarlanmasına yönelik bir örnek olay incelemesi. Journal of Tourism and Gastronomy Studies, 5 (2), 64-76.

Beyazıt, M. (2009). Yok olan kültür varlıklarımızdan Denizli'deki kurşunoğlu konağı. Belleten, 73 (268), 681-702.

Birdir, K., ve Akgöl, Y. (2015). Gastronomi turizmi ve Türkiye'yi ziyaret eden yabanc1 turistlerin gastronomi deneyimlerinin değerlendirilmesi. İsletme ve İktisat Dergisi, 3 (2), 57-68.

Büyüköztürk, Ş., Çakmak, E., Akgün, Ö. E; Karadeniz, Ş., ve Demirel, F. (2010). Bilimsel araştırma yöntemleri. (6. Bs.). Pegem Akademi Yayıncılık.

Creative cities network. (t.y). 15 Kasım 2021 tarihinde https://en.unesco.org/creativecities/afyonkarahisar. adresinden erişildi.

Du Rand, G. E., ve Heath, E. (2006). Towards a framework for food tourism as an element of destination marketing. Current issues in tourism, 9 (3), 206-234.

Durlu, F. Ö., Sünnetçioğlu, S. ve Can, A. (2013). Sürdürülebilir gastronomi turizmi hareketliliğinde coğrafi işaretlemenin rolü. Journal of Tourism and Gastronomy Studies, 1/1 (2013), 13-20.

Erdem, Ö., Mızrak, M., ve Kemer, A. K. (2018). Yöresel yemeklerin bölge restoranlarında kullanılma durumu: Mengen örneği. Uluslararası Türk Dünyası Turizm Araştırmaları Dergisi, 3 (1), 44-61.

Çağlı, I. B. (2012). Türkiye'de yerel kültürün turizm odaklı kalkinmadaki rolü: Gastronomi turizmi örneği. [Yüksek lisans tezi], İstanbul Teknik Üniversitesi.

Çapar, G., ve Yenipınar, U. (2016). Somut olmayan kültürel miras kaynağı olarak yöresel yiyeceklerin turizm. Journal of Tourism and Gastronomy Studies, 4 (1), 100-115.

Çepni, S. (2009). Araştırma ve proje çalışmalarına giriş. (4. Baskı). Celepler Matbaacılık.

Dağ, T. (2020). Geleneksel peynirlerin gastronomi turizmi açısından değerlendirilmesi: İzmir örneği. [Yüksek lisans tezi], Nevşehir Hacı Bektaş Üniversitesi. 
García-Hernandez, M., M., de la Calle-Vaquero, M., ve Yubero, C. (2017). Cultural heritage and urban tourism: Historic city centres under pressure. Sustainability, 9 (8), 1-19.

Göğebakan, Y. (2015). Dünya üzerindeki kültürel varlıkların turizme ve ekonomiye katkısı. Sanat ve Tasartm Dergisi, 5 (2), 48-71.

Göker, G. (2011). Destinasyon çekicilik unsuru olarak gastronomi turizmi (Balıkesir ili örneği). [Yüksek lisans tezi], Balıkesir Üniversitesi.

Gülen M. (2017). Gastronomi turizmi potansiyeli ve geliştirilmesi kapsamında Afyonkarahisar ilinin değerlendirilmesi. Güncel Turizm Araştırmalar Dergisi, 1 (1), 31-42.

Hall, C.M., Sharples, L., Mitchell, R., Macionis, N. ve Cambourne, B. (Ed.). (2003). Food tourism around the world. Routledge.

Harrington, R. J. ve Ottenbacher, M.C. (2010). Culinary tourism- a case study of the gastronomic capital. Journal of Culinary Science \& Technology, 8 (1), 14-32.

Hatipoğlu, A., Zengin, B., Batman, O., ve Şengül, S. (2013). Yöresel yemeklerin, kırsal turizm işletmeleri mönülerinde kullanım düzeyleri: Gelveri Örneği. International Journal of Social and Economic Sciences, 3 (1), 06-11.

Hjalager, A. M. ve Richards, G. (2002). Tourism and gastronomy. Routledge.

Işkın, M. (2021). Türkiye'nin gastronomi turizmi gelişmişlik göstergeleri ve yerli turistlerin göstergelere ilişkin deneyim durumları. Journal of Tourism and Technology Resarch, 2 (1), 26-34.

Kaya, F. (2021). Gastronomi turizmi seyahat motivasyonları. S. Şengül ve A. Kurnaz (Ed.). Gastronomi Turizmi içinde (s. 197-220). Detay Yayıncılık.

Kervankıran, İ., ve Özdemir, M. (2013). Turizm yönüyle gelişmekte olan Afyonkarahisar ilinde turist algısı üzerine bir araştırma. Marmara Coğrafya Dergisi, (27), 117-142.

Kızıldemir, Ö. (2019). Afyonkarahisar mutfak kültürü üzerine bir değerlendirme. Journal of Tourism and Gastronomy Studies, 7 (1), 647-663.

Kivela, J. ve Crotts, J. C. (2006). Tourism and gastronomy: Gastronomy's influence on how tourists experience a destination. Journal of Hospitality \& Tourism Research, 30 (3), 354-377.

Kocaman, S., Kayserili, A. ve Kaya, F. (2014). Kültürel coğrafya açısından bir araştırma: tarihi kağızman evleri. Doğu Coğrafya Dergisi, 32, 145-170.

Kunduracı, O. ve Bahargülü, N. (2018). Geleneksel Afyonkarahisar evlerinde cephe düzenlemeleri. SUTAD, (43), 491-522.

Kuş, E. (2003). Sosyal bilimlerde araştırma teknikleri nitel mi, nicel mi? Anı Yayıncılık.

Kurnaz, A., ve İşlek, E. (2018). Yöresel yemeklerin restoranlar tarafından kullanımının değerlendirilmesi: Marmaris örneği. International Journal of Social and Economic Sciences, 8(1), 50-59.

Özdemir, M. A. ve Kervankıran, İ. (2012). Afyonkarahisar ilinin turizm gelişimi ve çekicilikleri. Afyon Kocatepe University Journal of Social Sciences, 14 (1), 123-142.

Özleyen, E., ve Tepeci, M. (2017). Manisa'da yöresel yemeklerin ve lezzetlerin turizmin gelişimine katkısının. Turizm Akademik Dergisi, 4 (2), 139-152.

Pamukçu, H., Saraç, Ö., Aytuğar, S., ve Sandıkçı, M. (2021). The effects of local food and local products with geographical indication on the development of tourism gastronomy. Sustainability, 13 (12), 6692.

Privitera, D., Nedelcu, A., \& Nicula, V. (2018). Gastronomic and food tourism as an economic local resource: Case studies from Romania and Italy. GeoJournal of Tourism and Geosites, 21 (1), 143157.

Peštek, A. ve Činjarević, M. (2014). Tourist perceived image of local cuisine: the case of Bosnian food culture. British Food Journal. 116(11), 1821-1838.

Rinaldi, C. (2017). Food and gastronomy for sustainable place development: A multidisciplinary analysis of different theoretical approaches. Sustainability, 9 (10), 1748.

Ryu, K. ve Jang, S. (2006). Intention to experience local cuisine in a travel destination: the modified theory of reasoned action. Journal of Hospitality \& Tourism Research, 30 (4), 507-516.

Sandıkçı, M. ve Özkan, F. (2017, Kasım 23-25). Afyon kaymağı ve Afyonkarahisar mutfağındaki yeri. International Sustainable Tourisim Congress. (s. 852-859). Kastamonu- Türkiye: Kastamonu Üniversitesi Turizm Fakültesi.

Sandıkcı, M., Mutlu, H., ve Mutlu, A. S. (2020). Unesco gastronomi kenti Afyonkarahisar mutfağı üzerine yapılan çalışmaların bibliyometrisi. Türk Turizm Araştırmaları Dergisi, 4 (3), 2527-2541. 
Saraç, Ö. ve Tanrısever, C. (2018). Kastamonu'da yeniden işlevlendirilen tarihi yapıların sürdürülebilirliğine etki eden çekicilik faktörleri. Anatolia: Turizm Araştırmaları Dergisi, 29 (2), 151-163.

Sarışık, M. ve Özbay, G. (2015). Gastronomi turizmi üzerine bir literatür incelemesi. Anatolia: Turizm Araştırmaları Dergisi, 26 (2), 264-278.

Savarin, B. (2015). Gastronominin fizyolojisi. Oğlak Yayıncılık.

Scarpato, R. (2001). Gastronomy as a tourist product: The perspective of gastronomy studies. A. M. Hjalager ve G. Richards (Ed.). Tourism and Gastronomy içinde (s. 235). ATLAS.

Sezer, İ. (2017). Kültürel mirasın turizm açısından değerlendirilmesi: Taşköprü ilçesi örneği. Uluslararası Türk Dünyası Turizm Araştırmaları Dergisi, 2 (2), 175-198.

Şeker, İ. T. ve Hastaoğlu, E. (2020). Gastronomi turizmi kapsamında sivas yöresel yemeklerinin mikro ve makro besin öğelerinin incelenmesi. Atatürk Üniversitesi Sosyal Bilimler Enstitüsü Dergisi, 24 (4), 1879-1894.

Şengül, S. ve Türkay, O. (2016). Akdeniz mutfak kültürünün gastronomi turizmi bağlamında değerlendirilmesi. Journal of Tourism and Gastronomy Studies, 4(1), 86-99.

Tanrısever, C., Saraç, Ö. ve Aydoğdu, A. (2016). Yeniden işlevlendirilen tarihi yapıların sürdürülebilirliği, İktisat ve Girişimcilik Üniversitesi, Türk Dünyası Kırgız - Türk Sosyal Bilimler Enstitüsü, Celalabat - Kırgızistan, Akademik Bakış Dergisi, 54, 1068-1082.

TÜRSAB. (2015). TÜRSAB Gastronomi Turizmi Raporu. TÜRSAB. http://www.tursab.org.tr/dosya/12302/tursab-gastronomi-turizmi-raporu_12302_3531549.pdf.

Uyar, H. ve Zengin B. (2005). Gastronomi turizminin altenatif turizm çeşidi olarak değerlendirilmesi bağlamında gastronomi turizm indeksinin oluşturulması. Akademik Sosyal Araştırmalar Dergisi, 3 (17), 355-376.

Ültay, E., Akyurt, H., ve Ültay, N. (2021). Sosyal bilimlerde içerik analizi. IBAD Sosyal Bilimler Dergisi, 2021 (10), 188-201.

Wilson, S., Fesenmaier, D. R., Fesenmaier, J. ve Van Es, J. C. (2001). Factors for success in rural tourism development. Journal of Travel research, 40(2), 132-138.

Yazıt, H. (2021). Gastronomi turizminin tarihsel gelişimi. S. Şengül ve A. Kurnaz (Ed.). Gastronomi Turizmi içinde, (s. 45-61). Detay Yayıncılık.

Yücel, R., Şengül, S. ve Bayhan, İ. (2017, Kasım 23-25). Sürüdürebilir turizm: girişimlerinde önem ve performans değerlendirmeleri: Göynük tarihi konakları örneği. International Sustainable Tourism Congress (s. 432-446). Kastamonu: Kastamonu Üniversitesi Toruisim Faculty.

Zengin, B. ve Gürkan, A. S. (2019). Afyonkarahisar mutfağının gastronomi turizmi açısından değerlendirilmesi. Safran Kültür ve Turizm Araştırmaları Dergisi, 2 (2), 225-240.

Zengin, B. ve Işkın, M. (2017). Yerel mutfakların gastronomi turizmi açısından değerlendirilmesi: Sivas örneği. Akademik Sosyal Araştırmalar Dergisi, 5 (40), 404-415.

\section{Etik kurul onayı}

Afyon Kocatepe Üniversitesi sosyal ve beşeri bilimleri bilimsel araştırma ve yayın etik kurulu tarafından 26.05.2021 tarih ve 23708 sayılı etik kurul onayı alınmıştır.

\section{Araştırmacıların katkı oranı beyanı}

Yazarlar çalışmaya eşit oranda katkı sağlamıştır.

Çıkar çatışması beyanı

$\mathrm{Bu}$ çalışmada herhangi bir potansiyel çıkar çatışması bulunmamaktadır. 